\title{
EXERGY ANALYSIS OF THE ORGANIC RANKINE CYCLE BASED ON THE PINCH POINT TEMPERATURE DIFFERENCE
}

\author{
A.H. Bademlioglu1, ${ }^{1}$, R. Yamankaradeniz², O. Kaynakli²
}

\begin{abstract}
Organic Rankine Cycle (ORC) is a system that uses working fluids with hydrocarbon components instead of water and generates power from the heat recovery of different heat sources. In this study, the exergy analysis of a simple ORC, which produces electrical energy with the help a geothermal source $\left(125^{\circ} \mathrm{C}\right)$, was performed. R123, R152a, R245fa and R600a were determined as the fluids to be used in the Cycle. In this analysis, which was carried out according to the pinch point temperature differences $\left(5-20^{\circ} \mathrm{C}\right)$ in the evaporator, the exergy performance of the cycle components was evaluated for the geothermal resource unit flow rate and the variation of the exergy efficiency of the system was calculated. With the increase of the pinch point temperature difference in the evaporator, the decrease of the system's exergy efficiency became maximal $(11.7 \%)$ with the use of R152a as a refrigerant and the loss in the system's exergy efficiency became minimal $(9.03 \%)$ with the use of R123 as a refrigerant.
\end{abstract}

\section{Keywords: Organic Rankine Cycle, Exergy Analysis, Pinch Point Temperature, Refrigerant, Geothermal Source}

\section{INTRODUCTION}

The Rankine cycle is a thermodynamic cycle that converts heat energy into work and water is used as the working fluid in this cycle. The water used in the cycle is preferred to generate electricity in medium and large power plants. In the recent years, hydrocarbon-based fluids with lower critical temperature and pressure, higher molecular mass and less corrosion hazard have started to be used in the Rankine cycle instead of water. With the use of these fluids, these systems have taken the name of the Organic Rankine cycle (ORC). Being used in applications such as recycling of waste heat in factories, solar energy and especially in geothermal applications, the importance of this cycle is increasing day by day in terms of energy efficiency.

Thermodynamic properties of certain fluids used in the Rankine cycle are presented in Table 1. Many studies have shown that; among the hydrocarbon compound organic fluids used in the ORC systems, the ones that have higher molecular mass, low critical temperature and pressure and that are dry and isentropic in the meantime are more appropriate [1-5]. Wang et al. [6] investigated the performance of the ORC systems, which work around the critical range, in terms of thermodynamics. Ergun et al. [7] conducted extensive research on the application areas of ORC systems, and made suggestions for ORC systems that could be used in Turkey. Kaynakli et al. [8] studied on the thermodynamic analysis of a basic and simple ORC for some determined operation conditions in which auxiliary heat exchanger does not exist. Akkaya [9] examined an Organic Rankine Cycle based power generation system, which uses the thermal energy of exhausted gases from an industrial plant. Cihan [10] modeled a system in which the organic Rankine cycle that operates with low-temperature waste heat is combined with the traditional vapor-compression refrigeration cycle. Wang et al. [11] studied a regenerative organic Rankine cycle to utilize the solar energy over a low temperature range using flat plate solar collectors. Kai et al. [12] optimized the ORC system parameters and examined the effects of these optimal parameters for six working fluids (Butane, R236fa, R227ea, R236ea, R245fa and R245ca). Gao et al. [13] examined the performance of solar based organic Rankine cycle through the various working conditions like inlet pressure and temperature of the turbine. Mago et al. [14] analysed the performance of some working fluids under different heat source temperatures and indicated that the boiling point of the working fluids has a strong influence on the system thermal efficiency.

Roy et al. [15] studied the outlet power, the system and second law efficiency, exergy destruction of the system and so on in the case of two different heat source temperatures Dai et al. [16] conducted parametric This paper was recommended for publication in revised form by Ozgen Acikgoz ${ }^{1}$ Department of Energy Systems Engineering, Bursa Technical University, Bursa, TURKEY ${ }^{2}$ Department of Mechanical Engineering, Uludag University, Bursa, TURKEY ${ }^{\star} E$-mail address: husnu.bademlioglu@btu.edu.tr 
optimization of ORC with exergy efficiency. Kerme et al. [17] analyzed the energetic and exergetic performance of organic Rankine cycle driven by solar energy received by parabolic trough solar collectors. Li et al. [18] explored the effect of the evaporating temperature on the system thermal and exergy efficiencies and the net power outlet of an ORC system. Yaglı et al. [19] compared the exergetic and thermal performance of a R245fa based subcritical and supercritical ORC for the recovery of exhaust waste gas heat of the combined heat and power engine, which is fuelled by biogas. Guo et al. [20] analyzed and compared the performance of an ORC with internal heat exchanger to that of a basic ORC, using R600a, R245fa and R290 as working fluids. This analysis is based on the locations of heat transfer pinch point.

Table 1. Thermodynamic properties of certain organic fluids [8]

\begin{tabular}{|l|c|c|c|c|c|c|}
\hline Organic Fluid & $\begin{array}{c}\text { Type of } \\
\text { Fluid }\end{array}$ & $\begin{array}{c}\text { Molecular } \\
\text { Mass (g/mol) }\end{array}$ & $\begin{array}{c}\text { Critical } \\
\text { Temperature } \\
(\mathbf{K})\end{array}$ & $\begin{array}{c}\text { Critical } \\
\text { Pressure } \\
\text { (Mpa) }\end{array}$ & ODV & GWP \\
\hline $\mathrm{R} 123\left(\mathrm{CHCl}_{2} \mathrm{CF}_{3}\right)$ & isentropic & 152.93 & 456.8 & 3.66 & 0.060 & 77 (low) \\
\hline $\mathrm{R} 134 \mathrm{a}\left(\mathrm{CF}_{2} \mathrm{CH}_{2} \mathrm{~F}\right)$ & wet & 102.03 & 374.2 & 4.06 & 0 & 1430 (medium) \\
\hline $\mathrm{R} 152 \mathrm{a}\left(\mathrm{C}_{2} \mathrm{H}_{4} \mathrm{~F}_{2}\right)$ & wet & 66.05 & 386.2 & 4.52 & 0 & 124 (low) \\
\hline $\mathrm{R} 236 \mathrm{fa}\left(\mathrm{CF}_{3} \mathrm{CH}_{2} \mathrm{CF}_{3}\right)$ & isentropic & 152.04 & 398.1 & 3.2 & 0 & 9810 (high) \\
\hline $\mathrm{R} 245 \mathrm{fa}\left(\mathrm{C}_{3} \mathrm{H}_{3} \mathrm{~F}_{5}\right)$ & isentropic & 134.05 & 427.2 & 3.64 & 0 & 1030 (medium) \\
\hline $\mathrm{R} 600 \mathrm{a}\left(\mathrm{C}_{4} \mathrm{H}_{10}\right)$ & dry & 58.1 & 408.1 & 3.65 & 0 & 3 (low) \\
\hline
\end{tabular}

In this study, exergy analysis of an Organic Rankine cycle sample that produces electrical energy was made using a geothermal source with a temperature of $125^{\circ} \mathrm{C}$. R123, R152a, R245fa and R600a were identified as fluids to be used in the cycle. In this analysis which is based on the pinch point temperature differences, pptd $\left(5-20^{\circ} \mathrm{C}\right)$ in the evaporator, the exergy performance of the cycle elements for the geothermal source unit flow rate was theoretically investigated and the change of the exergy efficiency of the system was calculated. The obtained results are shown in the figures. It is important to consider the pinch point temperature difference in order to determine the optimum working conditions and to optimal design the system. For this reason, one of the main contributions to this study is to perform detailed exergy analysis for the different refrigerants based on the varying pinch point temperature difference in the evaporator.

\section{MATERIAL AND METHODS}

The schematic diagram of Organic Rankine cycle in which exergy analysis is performed in this study is given in Figure 1 (a) and T-s diagram in Figure 1 (b).

Many studies $[4,6,8,14,19,20]$ in the literature show that the temperature difference between the refrigerant and the heat source has a significant effect on system performance. The minimum temperature difference between the evaporation temperature in the evaporator of refrigerant used in the cycle and the geothermal fluid temperature is defined as the pinch point temperature difference.

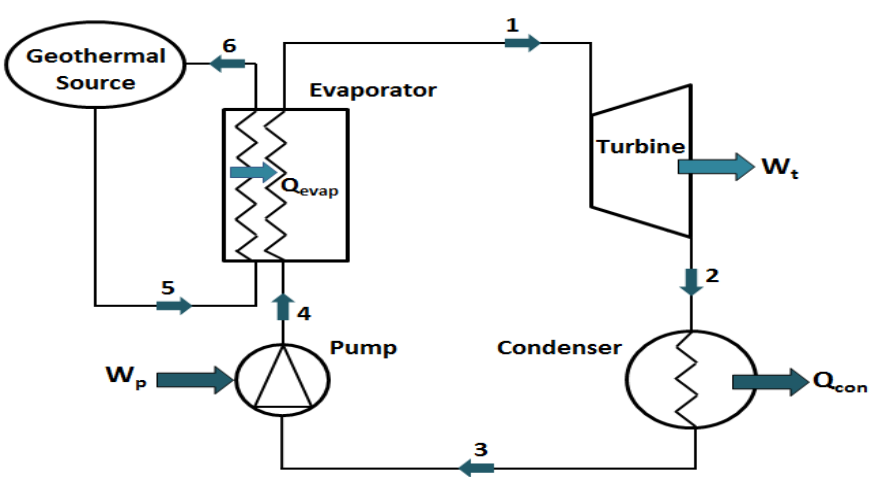

(a)

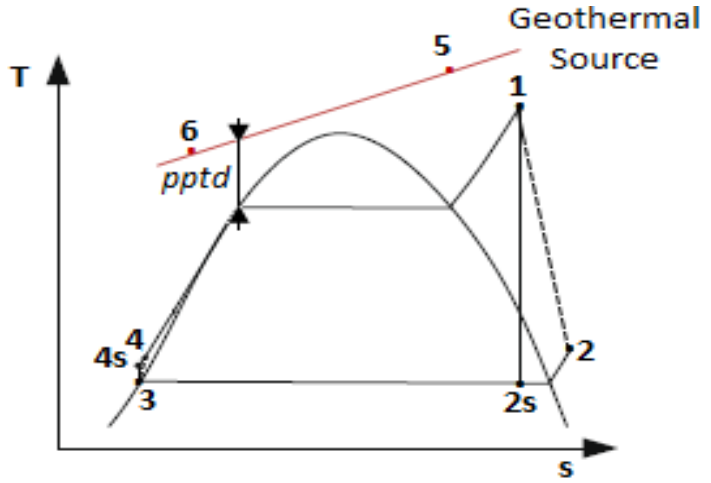

(b)

Figure 1. The schematic (a) and T-s (b) diagrams of Organic Rankine cycle 


\section{Exergy Analysis of Organic Rankine Cycle}

Within the scope of this study, it is aimed to make the exergy analysis of the cycle elements depending on the pinch point temperature difference in the evaporator by using the second law equations of thermodynamics and to calculate the exergy efficiencies depending on the exergy destruction [14,17,20,21].

For each point in the cycle, specific exergy is shown as $e_{i}$,

$$
e_{i}=h_{i}-h_{0}-\left[T_{0}\left(s_{i}-s_{0}\right)\right]
$$

Here, $T_{0}$ represents the dead-state temperature for exergy calculations, $h_{0}$ and $s_{0}$ stand for the enthalpy and entropy of the operating fluid in the dead-state conditions (at the pressure and temperature), respectively. For each point in the cycle, exergy $E_{i}$ is calculated with the equation,

$$
E_{i}=\dot{m}_{i} e_{i}
$$

Here, $\dot{m}_{i}$, the refrigerant flow rate for the points on the cycle (points 1,2,3,4) is used as $\dot{m}_{r e f}$ and geothermal resource flow are for the geothermal resource inlet and outlet points (5, 6 points) is used as $\dot{m}_{g e o}$.

Exergy balance for each process in the cycle is shown as,

$$
\sum E_{\text {input }}-\sum E_{\text {output }}=I
$$

\section{Exergy Analysis for the Steam Turbine}

Exergy destruction in the turbine between 1 and 2 is shown as,

$$
I_{t}=E_{1}-\left(E_{2}+W_{t}\right)
$$

Here, $W_{T}$ is the work obtained from the turbine. It is calculated by using the first law of thermodynamics equation as $W_{T}$,

$$
W_{t}=\dot{m}_{r e f}\left(h_{1}-h_{2}\right)
$$

Here, $h_{1}$ and $h_{2}$ are the enthalpy values at the inlet and outlet of the turbine, respectively. Exergy efficiency of the turbine, $\eta_{e x, T}$ is calculated by using the following equation,

$$
\eta_{e x, t}={ }^{W} /\left(E_{1}-E_{2}\right)
$$

\section{Exergy Analysis for the Condenser}

Exergy destruction in the condenser between 2 and 3 is shown as,

$$
I_{\text {con }}=T_{0}\left(\dot{m}_{r e f}\left(s_{2}-s_{3}\right)+Q_{c o n} / T_{c o n}\right)
$$

Here $Q_{c o n}$ is the heat rejected from the condenser and is calculated by using the first law equations of thermodynamics as $Q_{\text {con }}$,

$$
Q_{\text {con }}=m_{\text {ref }}\left(h_{2}-h_{3}\right)
$$

Exergy efficiency of the condenser, $\eta_{e x, c o n}$ is calculated by using the following equation,

$$
\eta_{e x, c o n}=1-\left(I^{I_{c o n}} /\left(E_{2}-E_{3}\right)\right)
$$

\section{Exergy Analysis for the Pump}

Exergy destruction in the pump between 3 and 4 is shown as,

$$
I_{P}=\left(E_{3}+W_{P}\right)-E_{4}
$$


Here, $W_{P}$, is the required work to compress the operating refrigerant in the pump. It is calculated by using the first law equations of thermodynamics as $W_{P}$,

$$
W_{P}=\dot{m}_{r e f}\left(h_{4}-h_{3}\right)
$$

Here $h_{3}$ and $h_{4}$ are the enthalpy values at the inlet and outlet of the pump. Exergy efficiency at the pump, $\eta_{e x, P}$ is calculated by using the following equation,

$$
\eta_{e x, P}=\left(E_{4}-E_{3}\right) /_{W_{P}}
$$

\section{Exergy Analysis for the Evaporator}

Exergy destruction in the evaporator between 4 and 1 is shown as,

$$
I_{\text {evap }}=\left(E_{4}+E_{5}\right)-\left(E_{1}+E_{6}\right)
$$

Here, points 5 and 6 are specified for the inlet and outlet points of the geothermal resource, respectively. $E_{5}$ and $E_{6}$ are the exergies at these points. Exergy efficiency in the evaporator, $\eta_{\text {ex,evap }}$ is calculated by using the equation,

$$
\eta_{\text {ex } \text { evap }}=\left(E_{1}-E_{4}\right) /\left(E_{5}-E_{6}\right)
$$

\section{Exergy Efficiency of the Cycle}

By using the second law equations of thermodynamics, exergy efficiency of the cycle is shown as $\eta_{\text {ex,cycle }}$

$$
\eta_{\text {ex,cycle }}=\left(W_{T}-\left|W_{P}\right|\right) /\left(E_{5}-E_{6}\right)
$$

In this study, the exergy analysis of the system is performed for the pinch point temperature difference in the evaporator by using the equations given above. Firstly, the flow rates of refrigerant have been determined for the unit flow rate of the geothermal source. Then, the thermophysical properties of each point in the system have been determined and the exergy changes at these points have been calculated. The exergy destruction in each component (evaporator, turbine, heat exchanger, condenser and pump) has been determined with the equations given above. Finally, the exergy efficiency of the cycle has been calculated by using Eq. (15).

\section{Assumptions}

In order to simplify the exergy analysis following assumptions are made;

- The system runs under steady-state conditions.

- Friction and heat losses as well as kinetic and potential energies are neglected.

- The evaporator capacity is fixed.

- The water at the outlet of condenser is saturated liquid.

- The specific volume of the working fluid remains constant during pumping.

- The efficiency of the turbine and pump is assumed to be constant for all working fluids.

- Chemical exergies of the substances are neglected.

\section{RESULTS AND DISCUSSION}

Design parameters and working conditions of system elements to be used for exergy analysis are given in Table 2.

In the exergy analysis made with the help of parameters given in Table 1 , point 1 is taken $8^{\circ} \mathrm{C}$ higher than the evaporation temperature in the evaporator so that refrigerant could be superheated steam in the turbine inlet. 
Table 2. Design parameters and operating conditions $[6,13]$

\begin{tabular}{|l|c|}
\hline Parameters & Value \\
\hline Evaporation temperature & $100^{\circ} \mathrm{C}$ \\
\hline Turbine inlet temperature & $108^{\circ} \mathrm{C}$ \\
\hline Geothermal water inlet temperature & $125^{\circ} \mathrm{C}$ \\
\hline Geothermal water pressure & $500 \mathrm{kPa}$ \\
\hline Pinch point temperature difference $($ pptd $)$ in the evaporator & $5-20^{\circ} \mathrm{C}$ \\
\hline Condensing temperature & $30^{\circ} \mathrm{C}$ \\
\hline Turbine isentropic efficiency & $85 \%$ \\
\hline Pump isentropic efficiency & $80 \%$ \\
\hline Ambient temperature & $20^{\circ} \mathrm{C}$ \\
\hline
\end{tabular}

For the geothermal resource unit flow rate, the change of the flow rates of different refrigerants is shown in Figure 2, which are used in the cycle depending on the pinch point temperature difference in the evaporator. As can be seen in the figure, refrigerant flow rates decrease because of the increase in pinch point temperature difference. With the increase of pinch point temperature difference from $5^{\circ} \mathrm{C}$ to $20^{\circ} \mathrm{C}$, the change of the flow rate of R123 becomes maximum and the flow rate drops from $0.60 \mathrm{~kg} / \mathrm{s}$ to $0.15 \mathrm{~kg} / \mathrm{s}$. However, the change of the flow rate of R600a becomes minimum and the flow rate drops from $0.36 \mathrm{~kg} / \mathrm{s}$ to $0.09 \mathrm{~kg} / \mathrm{s}$.

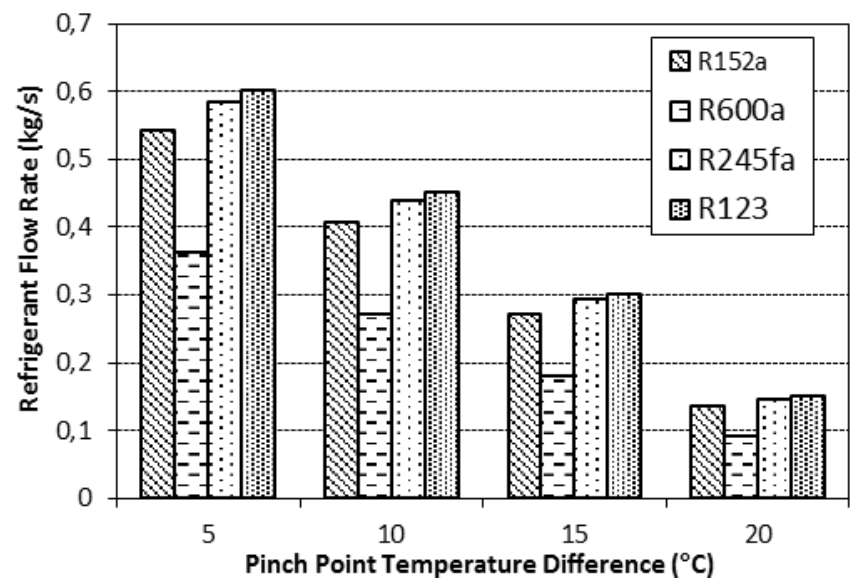

Figure 2. The change of the refrigerant flow rates depending on the pinch point temperature difference in the evaporator

For different refrigerants, the change of exergy destruction in the turbine is shown in Figure 3 depending on the pinch point temperature difference in the evaporator. As can be seen in the figure, the exergy destruction in the turbine is decreasing with the effect of increasing pinch point temperature difference. For the geothermal resource unit flow rate, while the decrease in exergy destruction in the turbine is maximum $(2.893 \mathrm{~kW})$ when $\mathrm{R} 152 \mathrm{a}$ is used in cycle, the decrease in exergy destruction in the turbine is minimum $(2.094 \mathrm{~kW})$ when R123 is used depending on the pinch point temperature difference. Depending on the refrigerants and operating conditions, the exergy destruction in the turbine is decreased by a maximum of about $74.93 \%$.

For different refrigerants, the change of exergy destruction in the pump is shown in Figure 4 depending on the pinch point temperature difference in the evaporator. As can be seen in the figure, the exergy destruction in the pump is decreasing with the effect of increasing pinch point temperature difference. For the geothermal resource unit flow rate, while the decrease in exergy destruction in the pump is maximum $(0.316 \mathrm{~kW})$ when 
$\mathrm{R} 152 \mathrm{a}$ is used in cycle, the decrease in exergy destruction in the pump is minimum $(0.05 \mathrm{~kW})$ when R123 is used depending on the pinch point temperature difference.

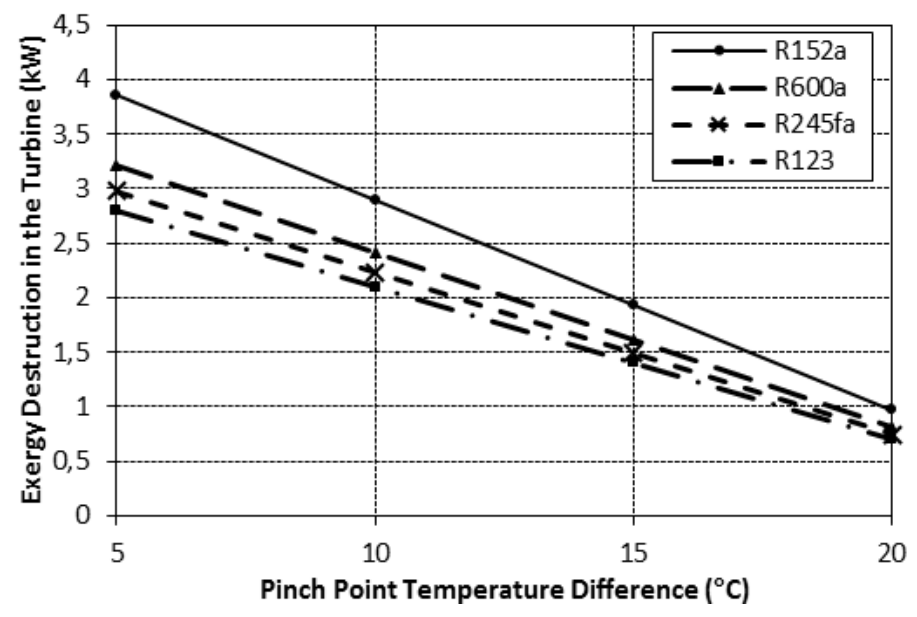

Figure 3. For different refrigerants, the change of exergy destruction in the turbine depending on the pinch point temperature difference in the evaporator

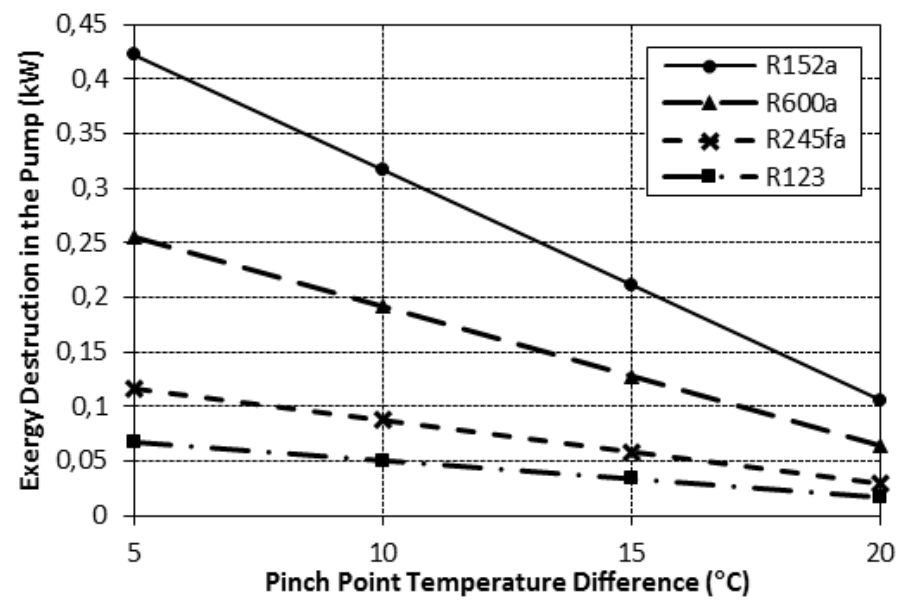

Figure 4. The change of exergy destruction in the pump depending on the pinch point temperature difference in the evaporator

For different refrigerants, the change of exergy destruction in the evaporator is shown in Figure 5 depending on the pinch point temperature difference in the evaporator. As can be seen in the figure, the exergy destruction in the evaporator is decreasing with the effect of increasing pinch point temperature difference. For the geothermal resource unit flow rate, while the decrease in exergy destruction in the evaporator is maximum $(4.492 \mathrm{~kW})$ when $\mathrm{R} 600 \mathrm{a}$ is used in cycle, the decrease in exergy destruction in the evaporator is minimum $(3.752 \mathrm{~kW})$ when R123 is used depending on the pinch point temperature difference. Depending on the refrigerants and operating conditions, the exergy destruction in the evaporator is decreased by a maximum of about $62.32 \%$.

The change of the outlet temperature of the geothermal fluid from the evaporator depending on the pinch point temperature difference in the evaporator is examined for different refrigerants in Figure 6 . As can be seen in the figure, the outlet temperature of geothermal fluid from evaporator is increasing with the effect of increasing pinch point temperature difference. Outlet temperature of geothermal fluid from the evaporator increases by maximum about $34 \%$ when $\mathrm{R} 152 \mathrm{a}$ is used and temperature rises from $86.1^{\circ} \mathrm{C}$ to $115.3^{\circ} \mathrm{C}$. Additionally, if R123 is used in the cycle, the maximum outlet temperature is obtained for different pinch point temperature differences. 


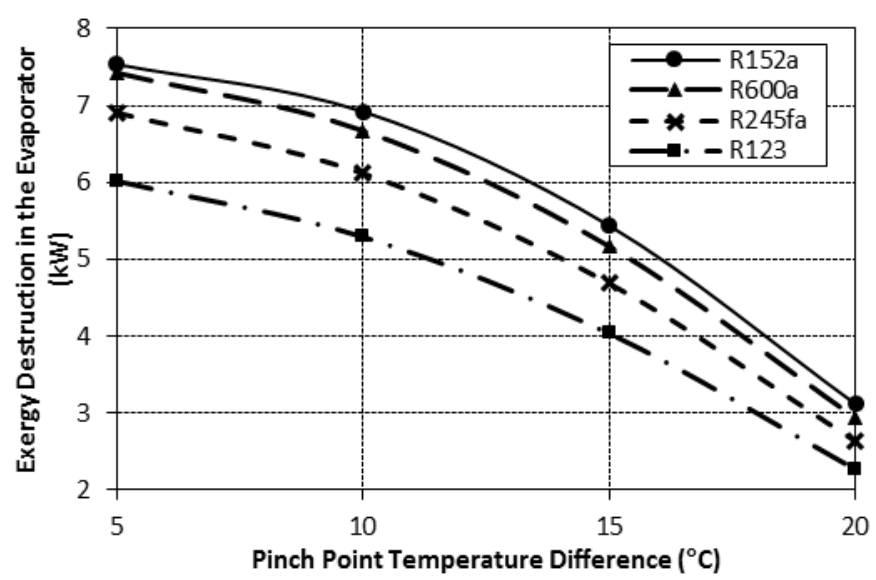

Figure 5. The change of exergy destruction in the evaporator depending on the pinch point temperature difference in the evaporator

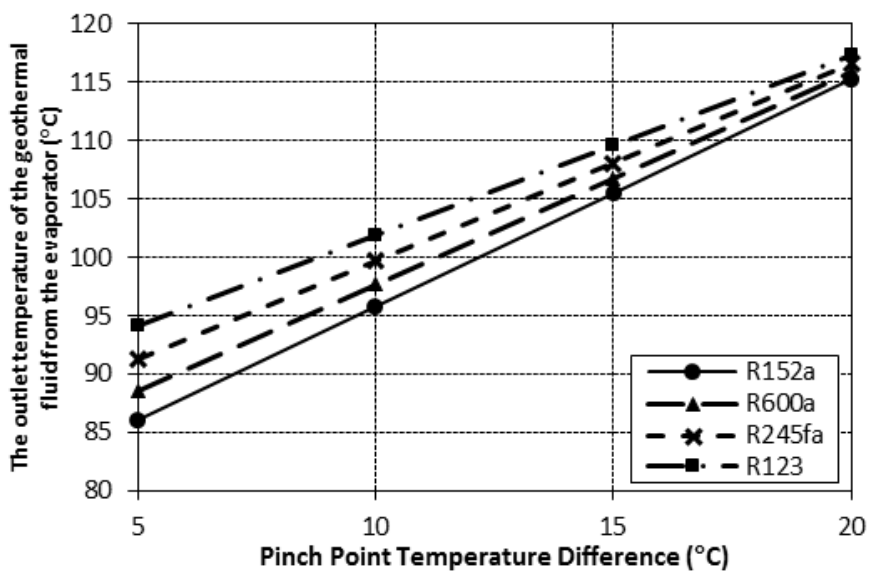

Figure 6. The change of outlet temperature of geothermal fluid from the evaporator depending on the pinch point temperature difference in the evaporator

For different refrigerants, the change of the exergy efficiency of cycle is shown in Figure 7 depending on the pinch point temperature difference in the evaporator. As can be seen in the figure, exergy efficiency of the cycle is decreasing with the effect of increasing pinch point temperature difference. When R152a is used as refrigerant in the cycle, the decrease in exergy efficiency of cycle is maximum and about $11.7 \%$ depending on the pinch point temperature difference. However, in case that R123 is used, the decrease in exergy efficiency of cycle is minimum and about $9.03 \%$.

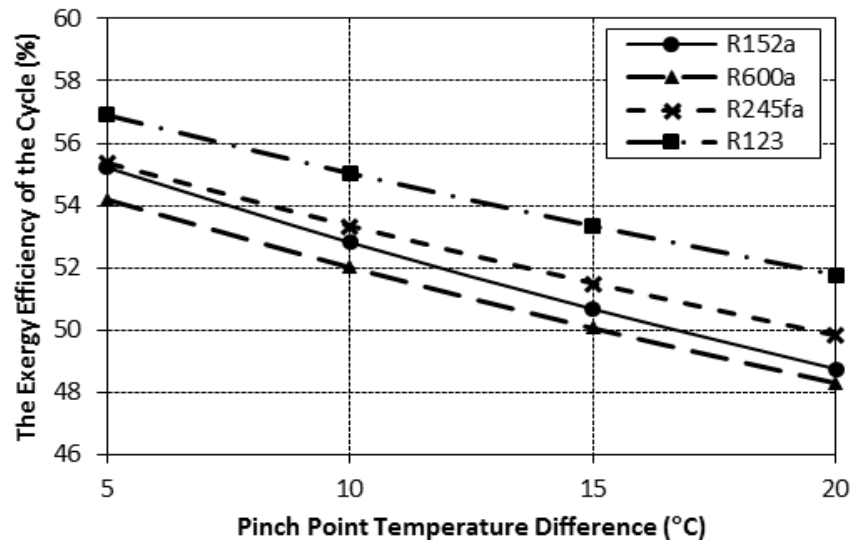

Figure 7. For different refrigerants, the change of exergy efficiency of the cycle depending on the pinch point temperature difference in the evaporator 


\section{CONCLUSION}

For a comprehensive thermodynamic evaluation in Organic Rankine cycles, exergy analysis should be done alongside energy analysis, as well. Within the scope of this study, the impact of pinch point temperature difference in the evaporator on the exergy performance is studied for different refrigerants. The results obtained:

- In general, the exergy efficiency of cycle decreases with the increase of pinch point temperature difference in the evaporator. For this reason it is recommended that the pinch point temperature difference be lower.

- Depending on the pinch point temperature difference, while the exergy loss in the cycle is maximum and about $11.7 \%$ when R152a is used, the exergy loss in the cycle is minimum and about $9.03 \%$ when R123 is used. Therefore, it is seen that R123 is more preferable as the refrigerant in the cycle.

- Depending on the refrigerant and the pinch point temperature difference, exergy destruction in the evaporator decreases about maximum of $62.32 \%$. Similarly, the exergy destruction in the turbine decreases about maximum of $74.93 \%$.

- The outlet temperature of geothermal fluid from the evaporator increases about maximum of $34 \%$ depending on the pinch point temperature difference when R152a is used as the working fluid in the cycle.

\section{NOMENCLATURE}

$\begin{array}{ll}\text { e } & \text { Specific exergy }(\mathrm{kJ} / \mathrm{kg}) \\ \mathrm{E} & \text { Exergy }(\mathrm{kW}) \\ \mathrm{I} & \text { Exergy destruction }(\mathrm{kW}) \\ \mathrm{m} & \text { Refrigerant flow rate }(\mathrm{kg} / \mathrm{s}) \\ \mathrm{T} & \text { Temperature }\left({ }^{\circ} \mathrm{C}\right) \\ \mathrm{h} & \text { Enthalpy }(\mathrm{kJ} / \mathrm{kg}) \\ \mathrm{s} & \text { Entropy }(\mathrm{kJ} / \mathrm{kg} \mathrm{K}) \\ \eta_{\mathrm{ex}} & \text { Exergy efficiency }(\%) \\ \mathrm{W} & \text { Work }(\mathrm{kW}) \\ \mathrm{Q} & \text { Heat transfer rate }(\mathrm{kW}) \\ \mathrm{P} & \text { Pressure }(\mathrm{kPa}) \\ \mathrm{pptd} & \text { Pinch temperature difference in the evaporator }\left({ }^{\circ} \mathrm{C}\right) \\ \mathrm{t} & \text { Turbine } \\ \text { con } & \text { Condenser } \\ \mathrm{p} & \text { Pump } \\ \text { evap } & \text { Evaporator } \\ \text { geo } & \text { Geothermal } \\ \text { ref } & \text { Refrigerant } \\ 0 & \text { Dead states } \\ \mathrm{i} & \text { Point }\end{array}$

\section{REFERENCES}

[1] Bertrand, F.T., George, P., Gregory, L., Antonios, F. (2009). Fluid selection for a low-temperature solar Rankine cycle. Applied Thermal Engineering, 29, 2468-2476.

[2] Drescher, U., Bruggemann, D. (2007). Fluid selection for the Organic Rankine Cycle (ORC) in biomass power and heat plants. Applied Thermal Engineering, 27, 223-228.

[3] Rayegan, R.,Tao, X. (2011). A procedure to select working fluids for solar Rankine cycle (ORCs). Renewable Energy, 36, 659-670.

[4] He, C., Liu, C., Gao, H., Xie, H., Li, Y., Wu, S., Xu, J. (2012). The optimal evaporation temperature and working fluids for subcritical organic Rankine cycle. Energy, 38, 136-143.

[5] Quoilin, S., Van den Broeck, M., Declaye, S., Dewallef, P., Lemort, V. (2013). Techno-economic survey of Organic Rankine Cycle (ORC) systems. Renewable \& Sustainable Energy Reviews, 22, 168-186.

[6] Wang, Y., Ding, X., Tang, L., Weng, Y. (2016). Effect of evaporation temperature on the performance of organic Rankine Cycle in near-critical condition. ASME Journal of Energy Resources Technology, 138, 032001032008.

[7] Ergun, A., Ozkaymak, M., Kilıcaslan, E. (2016). Power generation applications with Organic Rankine Cycle from low temperature heat sources. Duzce University Journal of Science \& Technology, 4, 686-696. 
[8] Kaynakli, O., Bademlioglu, A.H., Yamankaradeniz, N., Yamankaradeniz, R. (2017). Thermodynamic analysis of the Organic Rankine Cycle and the effect of refrigerant selection on cycle performance. International Journal of Energy Applications and Technologies, 4, 101-108.

[9] Akkaya, A.V. (2017). Performance analyzing of an organic Rankine cycle under different ambient conditions. Journal of Thermal Engineering, 3, 1498-1504.

[10] Cihan, E. (2014). Cooling performance investigation of a system with an organic Rankine cycle using waste heat sources. Journal of Thermal Science and Technology, 34, 101-109.

[11] Wang, M., Wang, J., Zhao, Y., Zhao, P., Dai, Y. (2013). Thermodynamic analysis and optimization of a solar-driven regenerative organic Rankine cycle (ORC) based on flat-plate solar collectors. Applied Thermal Engineering, 50, 816-825.

[12] Kai, Z., Mi, Z., Yabo, W., Zhili, S., Shengchun, L., Jinghong, N. (2015). Parametric optimization of low temperature ORC system. Energy Procedia, 75, 1596-1602.

[13] Gao, W., Li, H., Xu, G., Quan, Y. (2014). Working fluid selection and preliminary design of a solar organic Rankine cycle system. Environmental Progress \& Sustainable Energy, 34, 619-626.

[14] Mago, P.J., Chamra, L.M., Somayaji, C. (2007). Performance analysis of different working fluids for use in Organic Rankine Cycles. Proceedings of the Institution of Mechanical Engineers, Part A: Journal of Power and Energy, 221, 255-264.

[15] Roy, J.P., Mishra, M.K., Mishra, A. (2011). Performance analysis of an Organic Rankine Cycle with superheating under different heat source temperature conditions. Applied Energy, 88, 2995-3004.

[16] Dai, Y.P., Wang, J.F., Lin, G. (2009). Parametric optimization and comparative study of organic Rankine cycle (ORC) for low grade waste heat recovery. Energy Conversion and Management, 50, 576-582.

[17] Kerme, E.D., Orfi, J. (2015). Exergy-based thermodynamic analysis of solar driven organic Rankine cycle. Journal of Thermal Engineering, 1, 192-202.

[18] Li, W., Feng, X., Yu, L.J., Xu, J. (2011). Effects of evaporating temperature and internal heat exchanger on organic Rankine cycle. Applied Thermal Engineering, 31, 4014-4023.

[19] Yagl, H., Koc, Y., Koc, A., Gorgulu, A., Tandiroglu, A. (2016). Parametric optimization and exergetic analysis comparison of subcritical and supercritical organic Rankine cycle (ORC) for biogas fuelled combined heat and power (CHP) engine exhaust gas waste heat. Energy, 111, 923-932.

[20] Guo, C., Du, X., Yang, L., Yang, Y. (2014). Performance analysis of organic Rankine cycle based on location of heat transfer pinch point in evaporator. Applied Thermal Engineering, 62, 176-186.

[21] Safarian, S., Aramoun, F. (2015). Energy and exergy assessments of modified Organic Rankine Cycles (ORCs). Energy Reports, 1, 1-7. 